\title{
Differences of Plasma Levels of Tryptophan, Serotonin, 5-Hydroxyindole Acetic Acid, and Kynurenine between Healthy People and Patients of Major Monopolar Depression at Various Age and Gender
}

\author{
Hiroi Tomioka',2, Junichi Masuda3 ${ }^{3}$ Akikazu Takada4*, Akira Iwanami1 \\ ${ }^{1}$ Department of Psychiatry, School of Medicine, Showa University, Tokyo, Japan \\ ${ }^{2}$ Department of Psychiatry, Showa University Northern Yokohama Hospital, Yokohama, Japan \\ ${ }^{3}$ Global Application Development Center, Shimadzu Corporation, Tokyo, Japan \\ ${ }^{4}$ International Projects on Food and Health (NPO), Tokyo, Japan \\ Email: ^takadaa@mwd.biglobe.ne.jp
}

How to cite this paper: Tomioka, H., Masuda, J., Takada, A. and Iwanami, A. (2020) Differences of Plasma Levels of Tryptophan, Serotonin, 5-Hydroxyindole Acetic Acid, and Kynurenine between Healthy People and Patients of Major Monopolar Depression at Various Age and Gender. Food and Nutrition Sciences, 11, 431-441. https://doi.org/10.4236/fns.2020.116031

Received: May 6, 2020

Accepted: May 31, 2020

Published: June 3, 2020

Copyright $\odot 2020$ by author(s) and Scientific Research Publishing Inc. This work is licensed under the Creative Commons Attribution International License (CC BY 4.0).

http://creativecommons.org/licenses/by/4.0/ (c) (i) Open Access

\begin{abstract}
Background: It is not well analyzed whether there are differences in plasma levels of tryptophan (TRP) metabolites between healthy control people (HC) and patients of major monopolar depression (MMD). Methods: Ultra high-speed liquid chromatography/mass spectrometry has been used for the simultaneous determination of plasma levels of tryptophan metabolites in depressive patients. Results: There are no significant differences between plasma levels of TRP between HC and MMD. Plasma levels of TRP of HC are higher in young men, young women, old men, and old women in this order. Serotonin (5-HT) levels are higher in MMD than HC. Plasma levels of 5-HIAA of HC are also higher than those of patients of MMD. Plasma levels of kynurenine (KYN) of healthy old men and old women are higher than those of young men and old women. Plasma levels of KYN are higher in old women and young men of MMD than those of HC. Conclusion: Plasma levels of 5-HT are higher in patients of MMD than those of $\mathrm{HC}$, which may suggest that use of drugs inhibiting the 5-HT transportation may increase plasma levels of 5-HT in MMD.
\end{abstract}

\section{Keywords}

Depression, Monopolar Depression, Bipolar Depression, Tryptophan, Serotonin, 5-Hydroxyindole Acetic Acid, Kynurenine, 3-Hydroxykynurenine, Kynurenic Acid, Anthranilic Acid, Xanthurenic Acid, Indole-3-Acetic Acid, SSRI (Selective 
Serotonin Reuptake Inhibitor), SNRI (Serotonin Norepinephrine Reuptake Inhibitor)

\section{Introduction}

Clinically useful antidepressant medications were discovered about 60 years ago [1]. Studies showed that these drugs increased synaptic concentrations of serotonin and norepinephrine [2] and this action was hypothesized to support their antidepressant action. Later, a range of antidepressant drugs has been developed that, with few exceptions, act to enhance monoamine neurotransmission.

It was recognized that the clinical onset of effectiveness of neurochemical and therapeutic effects of antidepressants had taken days or weeks. This finding led researchers to challenge the central role for acute monoamine potentiation in the mechanism of antidepressant action. Recent approaches have sought to target more directly the neurobiological processes that might underlie this delay.

Since the discovery of antidepressants such as the selective serotonin reuptake inhibitor (SSRIs), hundreds of millions of patients have taken antidepressants. In 2006, 5 of the 35 drugs with top sales in the USA were antidepressants [3].

Many randomized trials have been conducted with antidepressants. Statistically, significant benefits have been repeatedly demonstrated. However, some meta-analysis questioned the results [4] [5].

Cipriani A. et al. [6] reported the results of one of latest meta-analysis [6]. They reported the results of which the study is based on 522 double-blind studies, which included 116,477 patients randomly assigned to 21 individual first-generation and second-generation antidepressant drugs or placebo.

They concluded that all antidepressants were more efficacious than placebo in adults with major depressive disorder. Smaller differences between active drugs were found when placebo-controlled trials were included in the analysis.

The reason why there are conflicting results in meta-analyses of effectiveness of antidepressants may be due to the fact against depression which is not well explored.

Recently we succeeded in the simultaneous measurements of TRP metabolites including 5-HT 5-HIAA or KYN by using an ultra high speed liquid chromatography/mass spectroscopy (LC/MS) [7] [8] [9] [10].

We reported that age and gender differences of plasma levels of TRP metabolites disappeared in patients of major monopolar depression although differences of some metabolites levels were found in patients of some age and gender in bipolar depression [11].

We now report statistical differences of TRP metabolites of patients of major monopolar and bipolar depression at various age and gender.

\section{Statistics}

Statistical significance of the differences between groups was calculated accord- 
ing to one-way ANOVA. When ANOVA indicated a significant difference ( $\mathrm{p}<$ 0.05 ), the mean values of the treatment were compared using Tukey's least significant difference test at $\mathrm{p}<0.05$.

The statistical comparison between groups is analyzed by the two way ANOVA.

Statistical significance is expressed as followed. ${ }^{*} \mathrm{p}<0.05,{ }^{* *} \mathrm{p}<0.001$.

\section{Methods}

1) Patients; Outpatients of depression were recruited in this study. Patients were diagnosed using the criteria of Diagnostic and Statistical Manual of Mental Disorders, the 5th edition (DSM-5, American Psychiatric Association 2013) [12]. Fasting blood samples were taken early in the morning. Their severity of depression was checked by CGI-S [13], SDS [14], and HDR-S [15]. The history of prescriptions of drugs such as antidepressants, anxyolitics, mood stabilizers and other drugs were asked.

Further characteristics of patients are described below. Outpatients who showed symptoms of depression were recruited in the studies at the Department of Psychiatry of Showa University Northern Yokohama Hospital. Patients were required to have had no lifetime history of psychosis, personality disorder, or drug or alcohol misuse. We also excluded patients who had organic problems of the brains. This study was carried out from 2016 to 2019. All patients gave their consent in a written form after receiving comprehensive information on the study protocol.

2) Healthy volunteers; We asked volunteers to provide blood early morning before breakfast. The backgrounds of these people were reported elsewhere [9].

3) Measurements of TRP metabolites; Plasma factors were measured after plasma was separated from blood $\left(3000 \mathrm{rpm} / \mathrm{min}\right.$. at $\left.4^{\circ} \mathrm{C}\right)$. Ethylenediaminetetraacetic acid (EDTA) was used as an anticoagulant.

The simultaneous measurements of TRP metabolites in plasma were performed by using an ultra high speed liquid chromatography/spectrometry. Detailed methodology was described elsewhere [7] [8] [9] [10].

\section{Results}

4) Comparison of plasma levels of TRP, 5-HT, 5-HIAA and KYN between patients of MMD and healthy control.

Table 1 shows background and plasma levels of TRP metabolites.

${ }^{*}$; TRP

Sample name, old women < young men, young women and old men.

There was significant effect of sample name $(\mathrm{F}(3,105)=10.693, \mathrm{p}<0.01)$, but there was no significant effect of diagnosis $(\mathrm{F}(1,105)=2.365, \mathrm{p}=0.127)$, and there was no significant interaction between diagnosis and sample name $(\mathrm{F}(3$, 105) $=2.088, \mathrm{p}=0.106$ )

Tukey's post hoc test showed that TRP level of old women was lower than that 
Table 1. Comparison of tryptophan metabolites between HC and MDD.

\begin{tabular}{|c|c|c|c|c|c|c|c|c|c|}
\hline \multirow{2}{*}{$\begin{array}{c}\text { Diagnosis } \\
\text { sample name }\end{array}$} & \multicolumn{4}{|c|}{$\mathrm{HC}(\mathrm{n}=38)$} & \multicolumn{4}{|c|}{$\operatorname{MDD}(n=38)$} & \multirow[b]{2}{*}{$\begin{array}{l}\text { significant } \\
\text { differences }\end{array}$} \\
\hline & $\begin{array}{l}\text { young men } \\
\quad(n=25)\end{array}$ & $\begin{array}{l}\text { young } \\
\text { women } \\
(\mathrm{n}=10)\end{array}$ & $\begin{array}{l}\text { old men } \\
(n=20)\end{array}$ & $\begin{array}{l}\text { old women } \\
\quad(n=20)\end{array}$ & $\begin{array}{l}\text { young men } \\
\quad(n=7)\end{array}$ & $\begin{array}{l}\text { young } \\
\text { women } \\
(n=18)\end{array}$ & $\begin{array}{l}\text { old men } \\
(n=3)\end{array}$ & $\begin{array}{l}\text { old women } \\
(n=10)\end{array}$ & \\
\hline Tryptophan $(\mu \mathrm{M})$ & $\begin{array}{c}63.92 \pm \\
10.84\end{array}$ & $67.79 \pm 9.30$ & $\begin{array}{c}68.89 \pm \\
13.32\end{array}$ & $47.68 \pm 7.19$ & $\begin{array}{c}64.09 \pm \\
13.77\end{array}$ & $\begin{array}{c}58.48 \pm \\
10.40\end{array}$ & $\begin{array}{c}59.11 \pm \\
2.026\end{array}$ & $\begin{array}{c}51.24 \pm \\
11.01\end{array}$ & ${ }^{\star} 1$ \\
\hline Serotonin (nM) & $1.29 \pm 1.97$ & $\begin{array}{c}42.90 \pm \\
35.49\end{array}$ & $\begin{array}{c}68.61 \pm \\
90.31\end{array}$ & $4.49 \pm 6.03$ & $\begin{array}{c}325.6 \pm \\
351.4\end{array}$ & $\begin{array}{c}267.6 \pm \\
204.4\end{array}$ & $\begin{array}{c}120.3 \pm \\
96.01\end{array}$ & $\begin{array}{c}160.2 \pm \\
145.2\end{array}$ & ${ }^{\star} 2$ \\
\hline Kynurenine (nM) & $\begin{array}{c}713.18 \pm \\
136.02\end{array}$ & $\begin{array}{c}1588.09 \pm \\
313.52\end{array}$ & $\begin{array}{c}1696.82 \pm \\
1074.65\end{array}$ & $\begin{array}{c}719.94 \pm \\
173.87\end{array}$ & $\begin{array}{c}2506.5 \pm \\
1042.9\end{array}$ & $\begin{array}{c}1653.0 \pm \\
510.16\end{array}$ & $\begin{array}{c}1014.2 \pm \\
418.25\end{array}$ & $\begin{array}{c}1666.4 \pm \\
534.60\end{array}$ & $* 3$ \\
\hline $\begin{array}{l}\text { 5-Hydroxyindoleacetic } \\
\text { acid (nM) }\end{array}$ & $9.00 \pm 1.92$ & $30.87 \pm 9.55$ & $\begin{array}{c}33.15 \pm \\
12.57\end{array}$ & $13.17 \pm 3.30$ & $\begin{array}{c}28.04 \pm \\
22.07\end{array}$ & $\begin{array}{c}35.00 \pm \\
28.99\end{array}$ & $\begin{array}{c}22.82 \pm \\
28.11\end{array}$ & $\begin{array}{c}48.68 \pm \\
58.22\end{array}$ & ${ }^{\star} 4$ \\
\hline
\end{tabular}

Two-way ANOVA with diagnosis (HC and MDD) and sample name (young and old men and women) was used for evaluating statistical significance.

of young men $(\mathrm{p}<0.01)$, young women $(\mathrm{p}<0.01)$, and old men $(\mathrm{p}<0.01)$.

${ }^{*} 2$; Serotonin

Diagnosis, HC $(18.259 \pm 43.138 \mathrm{nM})<\operatorname{MDD}(250.150 \pm 226.639 \mathrm{nM})$.

There was significant effect of diagnosis $(\mathrm{F}(1,86)=30.685, \mathrm{p}<0.01)$, but there was no significant effect of sample name $(F(3,86)=1.544, \mathrm{p}=0.209)$, and there was no significant interaction between diagnosis and sample name $(\mathrm{F}(3,86)=$ $2.583, \mathrm{p}=0.059)$.

\#3; KYN

Sample name, $\mathrm{F}(3,105)=2.931, \mathrm{p}<0.05$;

Diagnosis, $\mathrm{F}(1,105)=14.380, \mathrm{p}<0.01$;

Sample name ${ }^{\star}$ diagnosis, $\mathrm{F}(3,105)=13.474, \mathrm{p}<0.01$.

In HC, KYN level of young men was lower than young women $(\mathrm{p}<0.01)$ and old men $(\mathrm{p}<0.01)$.

And KYN level of old women was lower than young women $(\mathrm{p}<0.01)$ and old men $(\mathrm{p}<0.01)$.

In MDD, KYN level of young men was higher than *young women $(\mathrm{p}<0.05)$, old men ( $\mathrm{p}<0.01)$ and old women $(\mathrm{p}<0.05)$.

In young men and old men, KYN level of MDD was higher than $\mathrm{HC}(\mathrm{p}<$ $0.01)$.

*4; 5-HIAA

Sample name, $\mathrm{F}(3,105)=1.849, \mathrm{p}=0.143$;

Diagnosis, $\mathrm{F}(1,105)=5.273, \mathrm{p}<0.05$;

Sample name *diagnosis, $\mathrm{F}(3,105)=3.475, \mathrm{p}<0.05$.

In HC, 5-HIAA level of old men was higher than young men $(\mathrm{p}<0.01)$ and old women $(\mathrm{p}<0.05)$.

Plasma levels of 5-HIAA were higher in patients of MMD than HC $(19.4668 \pm$ $13.0980 \mathrm{nM})<\operatorname{MDD}(36.3560 \pm 37.4453 \mathrm{nM})$.

5; Plasma levels of TRP in HC and patients of MDD

Figure 1 shows that there was no significant difference between TRP levels of 
HC and patients of MMD. There are differences in plasma levels of TRP among $\mathrm{HC}$ of different age and gender.

Tukey's post hoc test showed that TRP level of old women was lower than that of young men $(\mathrm{p}<0.01)$, young women $(\mathrm{p}<0.01)$, and old men $(\mathrm{p}<0.01)$.

6; Plasma levels of 5-HT in HC and patients of MMD

Figure 2 shows that plasma levels of 5-HT are higher in MMD than those of HC. Two-way ANOVA with diagnosis (HC and MDD) and sample name (young and old men and women) was used for evaluating statistical significance.

7; Plasma levels of KYN in $\mathrm{HC}$ and patients of MMD

Figure 3 shows that Plasma levels of KYN are higher in patients of MMD than those of HC. Plasma levels of KYN are higher in young men than young women, old men and old women in MMD. In HC, plasma levels of KYN are higher young women and old men than young men and old women.

8; Plasma levels of 5-HIAA in HC and patients of MMD

Figure 4 shows that there is no significant difference between plasma levels of 5-HIAA of HC and patients of MMD. In HC, plasma levels of 5-HIAA of old men are higher than those of young men and old women.

Two-way ANOVA with diagnosis (HC and MDD) and sample name (young and old men and women) was used for evaluating statistical significance.

Plasma levels of 5-HIAA were higher in patients of MMD than HC (19.4668 \pm $13.0980 \mathrm{nM})<\operatorname{MDD}(36.3560 \pm 37.4453 \mathrm{nM})$.

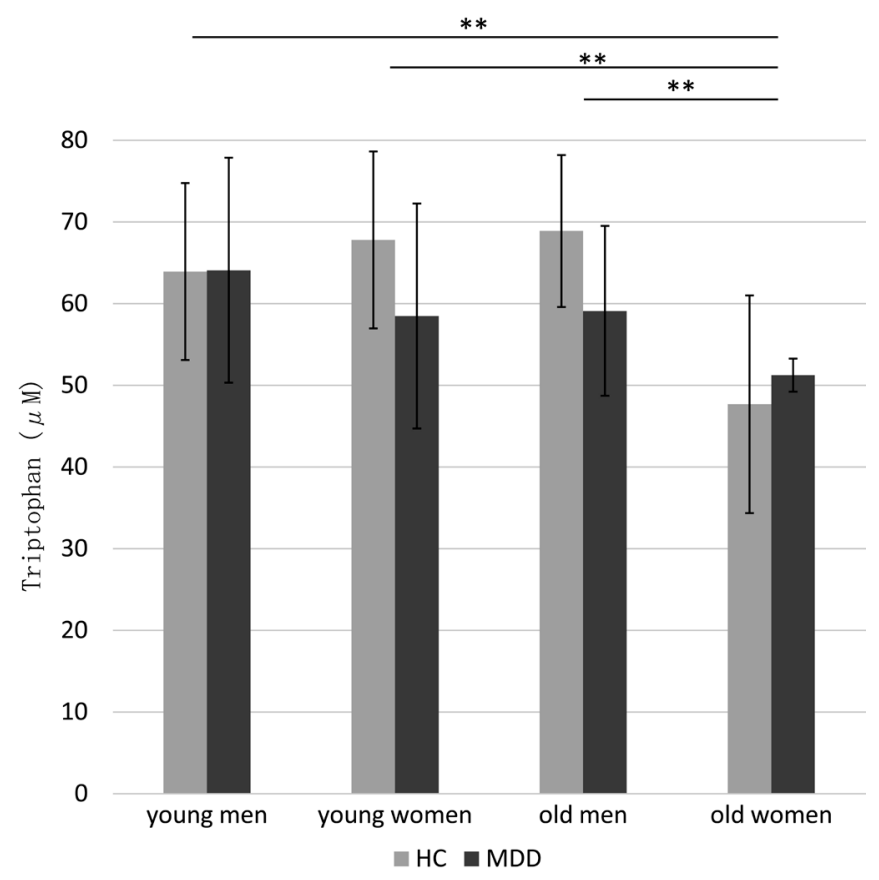

Two-way ANOVA with diagnosis (HC and MDD) and sample name (young and old men and women) was used for evaluating statistical significance. ${ }^{*}$ Sample name, old women $<$ young men, young women and old men. There was significant effect of sample name $(F(3,105)=10.693, p<$ $0.01)$, but there was no significant effect of diagnosis $(F(1,105)=2.365, p=0.127)$, and there was no significant interaction between diagnosis and sample name $(F(3,105)=2.088, \mathrm{p}=0.106)$.

Figure 1. Plasma levels of TRP in HC and patients of MMD. 


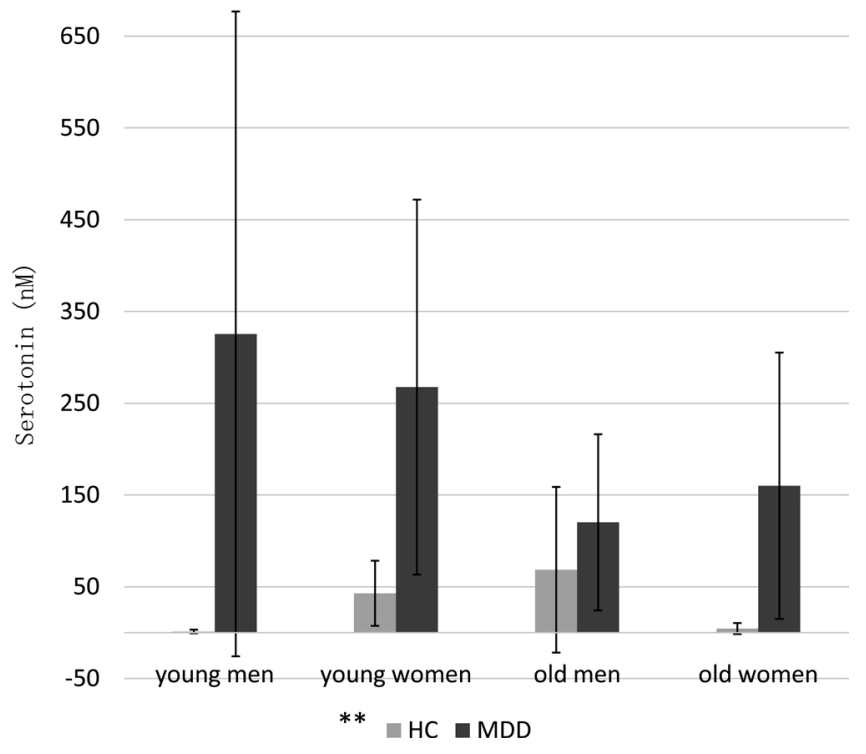

Two-way ANOVA with diagnosis (HC and MDD) and sample name (young and old men and women) was used for evaluating statistical significance. ${ }^{\star *}$ Diagnosis, HC $(18.259 \pm 43.138 \mathrm{nM})<$ $\operatorname{MDD}(250.150 \pm 226.639 \mathrm{nM})$. There was significant effect of diagnosis $(\mathrm{F}(1,86)=30.685, \mathrm{p}<0.01)$, but there was no significant effect of sample name $(F(3,86)=1.544, p=0.209)$, and there was no significant interaction between diagnosis and sample name $(F(3,86)=2.583, \mathrm{p}=0.059)$.

Figure 2. Plasma levels of 5-HT in HC and patients of MMD.

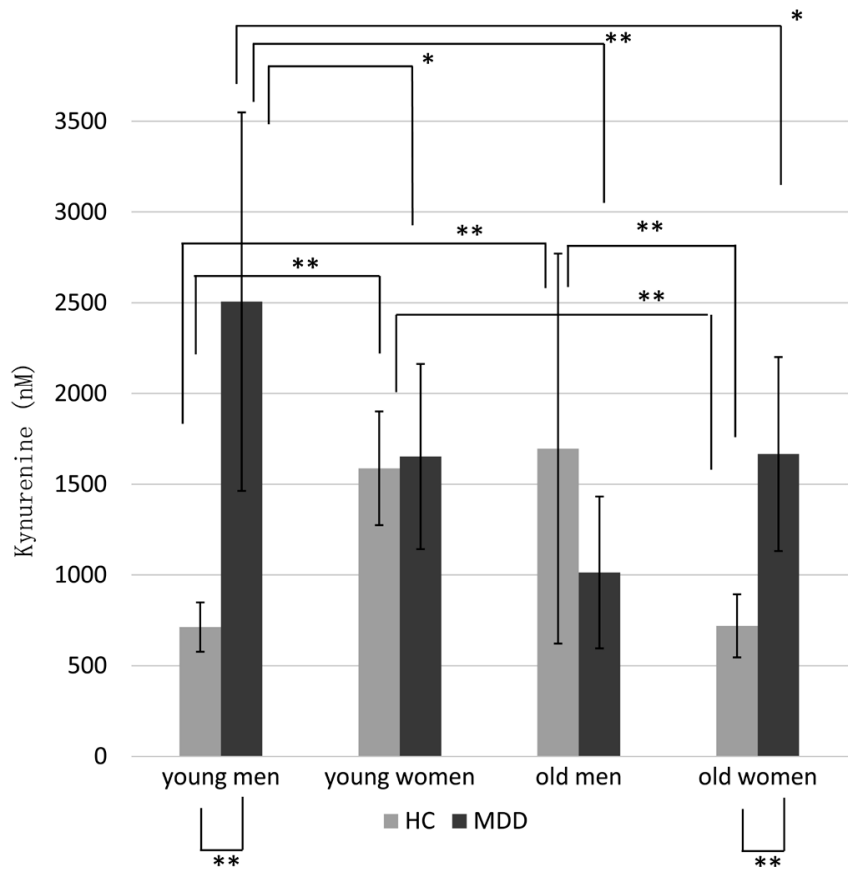

Two-way ANOVA with diagnosis (HC and MDD) and sample name (young and old men and women) was used for evaluating statistical significance. Sample name, $F(3,105)=2.931, p<0.05$; Diagnosis, $\mathrm{F}(1,105)=14.380, \mathrm{p}<0.01$; Sample name ${ }^{*}$ diagnosis, $\mathrm{F}(3,105)=13.474, \mathrm{p}<0.01$. In HC, KYN level of young men were lower than young ${ }^{* *}$ women $(p<0.01)$ and ${ }^{* *}$ old men $(p<0.01)$. And KYN level of ${ }^{* *}$ old women were lower than ${ }^{* *}$ young women $(\mathrm{p}<0.01)$ and ${ }^{* *}$ old men $(\mathrm{p}<0.01)$. In MDD, KYN level of young men were higher than ${ }^{*}$ young women $(\mathrm{p}<0.05),{ }^{* *}$ old men $(\mathrm{p}<0.01)$ and ${ }^{*}$ old women $(\mathrm{p}<0.05)$. In ${ }^{*}$ young men and ${ }^{* *}$ old men, KYN level of MDD were higher than $\mathrm{HC}(\mathrm{p}<0.01)$.

Figure 3. Shows plasma levels of KYN in HC and patients of MMD. 


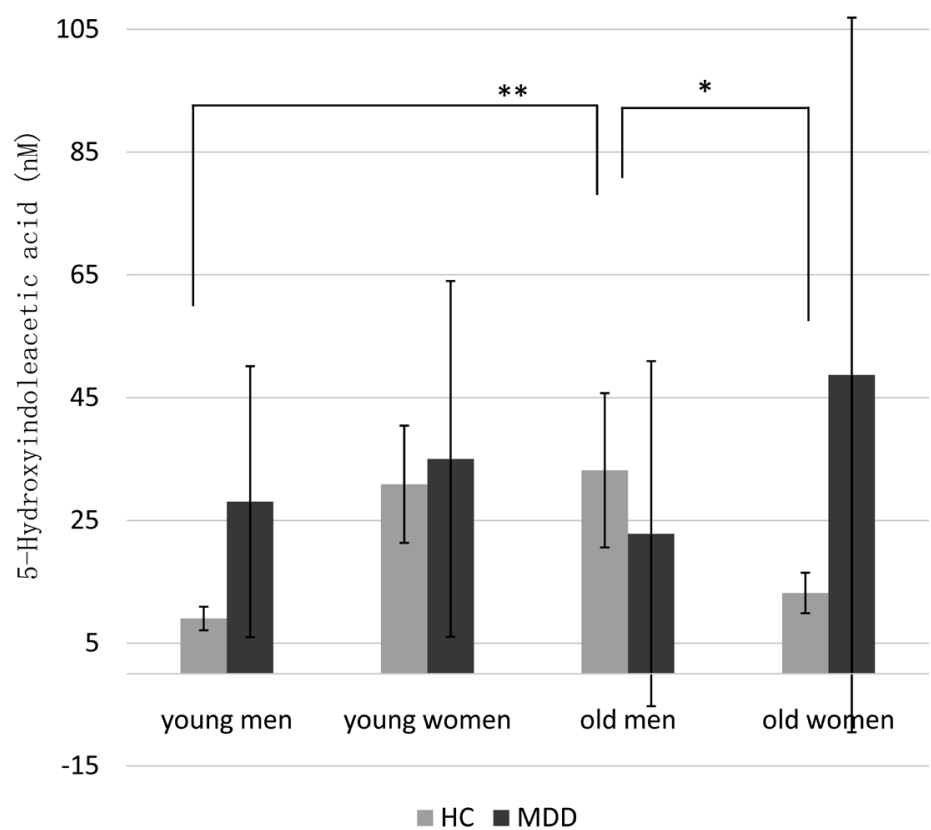

Two-way ANOVA with diagnosis (HC and MDD) and sample name (young and old men and women) was used for evaluating statistical significance. Sample name, $F(3,105)=1.849, \mathrm{p}=0.143$; Diagnosis, $\mathrm{F}(1,105)=5.273, \mathrm{p}<0.05$; Sample name *diagnosis, $\mathrm{F}(3,105)=3.475, \mathrm{p}<0.05$. In HC, 5 -HIAA level of old men were higher than ${ }^{* *}$ young men $(\mathrm{p}<0.01)$ and ${ }^{*}$ old women $(\mathrm{p}<0.05)$.

Figure 4. Plasma levels of 5-HIAA in HC and patients of MMD.

\section{Discussion}

Although roles of 5-HT in etiology of depression are implicated and extensively studied, it recently has been paid to the suggestion that depression has something to do with the activation of the immune system and inflammation [16]. Activated immune-inflammatory system may be induced by many factors of depression including psychosocial stressors and medical comorbidities.

Disturbances of KYN pathway is considered as a factor contributing to the pathogenesis of depression [17]. Indoleamine 2,3-dioxygenase (IDO) is the initial and rate limiting extrahepatic enzyme of KYN pathway. Chronic inflammation and stress were known to stimulate IDO activity, thus KYN pathway. It has been suggested that not only monoamine systems are involved in depression, neuroplasticity, immune system and KYN pathway may be involved in symptom improvement in depression [18].

Since roles of TRP metabolites in major monopolar depression or bipolar depression have not been studied well, we investigated changes in TRP metabolites in plasma of patients of MMD and BP by using a ultra high speed LQ/MS which we have succeeded for the first time in the world.

As to involvement of 5-HT in etiology of depression, it has been shown that 11 out of 16 studies have shown lower levels of 5-HIAA in the cerebrospinal fluid of patients suffering from an episode of major depression [19]. Since 5-HIAA is converted from 5-HT, such observation leads to the 5-HT deficiency hypothesis of suicidal behavior [20]. According to its hypothesis, serotonergic activity 
gives rise to an inhibitory effect on suicidal behavior.

Strangely, these findings do not support the idea that 5-HT levels are low in the brains of depressive patients.

Cell bodies in the dorsal and median raphe nuclei give serotonergic innervation throughout the brain. 5-HT is generated from TRP by tryptophan hydroxylase 2 (TPH2). Surprisingly, TPH2 levels in ventral frontal cortex of suicide victims are shown to be elevated [21]. In addition to increased expression of TPH2, the presence of more 5-HT neurons exists in the raphe nuclei of suicide victims [22] [23], indicating that 5-HT synthetic capacity increases in suicide victims.

These observations suggest the roles of 5-HT in depression are very much complicated and it cannot be said that 5-HT is deficient in the brain of depressive patients.

As to relationship between plasma levels of 5-HT or 5-HIAA and those in cerebrospinal fluid, it is shown that plasma free 5-HT correlated significantly with CSF 5-HT $(\mathrm{r}=0.411, \mathrm{p}<0.02)$, and plasma 5-HIAA correlated with the CSF 5 -HIAA/5-HT ratio $(\mathrm{r}=0.508, \mathrm{p}<0.004)$. The concentration of 5-HIAA in CSF correlated with the plasma 5-HIAA/5-HT ratio $(r=0.405, \mathrm{p}<0.026)$ (which can be taken as an index of monoamine oxidase type A activity in peripheral tissues) and with the platelet $5-\mathrm{HT} /$ plasma $5-\mathrm{HT}$ ratio $(\mathrm{r}=0.375, \mathrm{p}<0.05)$ [24]. The results of the measurements of 5-HT and 5-HIAA in the brain of suicide victims indicated that there is moderate increase in 5-HIAA levels in the hippocampus of suicide victims [25]. They concluded that there was no evidence of gross alteration of 5-HT mechanisms in suicide or depression.

5-HT transporters transfer 5-HT from the synaptic cleft to presynaptic neurons. Platelets also have 5-HT transporters. In suicide victims serotonin transporter binding was found to be lower in all but one of the 43 sampled regions. The reduction in binding was most pronounced in the ventrolateral prefrontal cortex, where the difference between suicides and controls ranged between 15\% and $27 \%$. Serotonin transporter and 5-HTIA binding were negatively correlated within the same brain areas, suggesting common regulatory factors with opposite effects on binding to the two receptors [26]. This finding explains why plasma levels of 5-HT were higher and those in the blood were lower in depression.

In preliminary studies we reported that plasma levels of 5-HT of young female $\mathrm{HC}$ are higher than those of young female patients of MMD [8]. At that time we measured plasma levels of 5-HT of patients who did not take drugs affecting the transportation of 5-HT into platelets.

In the present studies we increased number of patients who were given drugs such as SSRI (selective serotonin reuptake inhibitors) which affect 5-HT transportation of 5-HT of platelets, since 5-HT is not uptaken by platelets who were given SSRI or SNRI (serotonin-noradrenalin reuptake inhibitors).

It is also possible that 5-HT transporter binding may be decreased in patients of depression, which lower the uptake of 5-HT in platelets.

AS to 5-HIAA levels, we report that plasma levels of 5-HIAA were higher in 


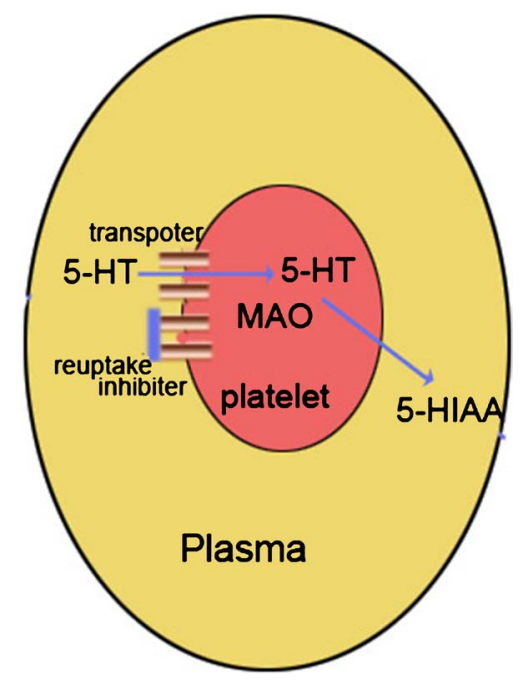

Figure 5. Uptake of 5-HT by platelets and degradation by MAO.

patients of MMD than HC. We suggested preliminarily that the activity of monoamine oxidase (MAO) was enhanced in platelets of patients of MMD [8]. The present data support this suggestion resulting in increased levels of 5-HIAA in spite of lower 5-HT uptake into platelets.

5 -HT is uptaken by transporter into platelet and degraded by monoamine oxydase (MAO) into 5-HIAA. Reuptake inhibiter such as SSRI (selective serotonin reuptake inhibitor) inhibits the uptake of 5-HT.

Figure 5 illustrates the uptake of 5-HT by transporters of platelets and its degradation by MAO into 5-HIAA.

The present results suggest that in analyzing the results of assays of 5-HT or 5-HIAA much attention has to be paid to drugs used.

\section{Conflicts of Interest}

The authors declare no conflicts of interest regarding the publication of this paper.

\section{References}

[1] Cahn, C. (2006) Roland Kuhn, 1912-2005. Neuropsychopharmacology, 31, 1096. https://doi.org/10.1038/sj.npp.1301026

[2] Ross, S.B. and Renyi, A.L. (1969) Inhibition of the Uptake of Tritiated 5-Hydroxytryptamine in Brain Tissue. European Journal of Pharmacology, 7, 270-277. https://doi.org/10.1016/0014-2999(69)90091-0

[3] Drugs.com. http://www.drugs.com/top 200.html

[4] Ioannidis, J.P. (2008) Effectiveness of Antidepressants: An Evidence Myth Constructed from a Thousand Randomized Trials? Philosophy, Ethics, and Humanities in Medicine, 3, 14. https://doi.org/10.1186/1747-5341-3-14

[5] Kirsch, I., Deacon, B.J., Huedo-Medina, T.B., Scoboria, A., Moore, T.J. and Johnson, B.T. (2008) Initial Severity and Antidepressant Benefit: Meta-Analysis of Data Submitted to the Food and Drug Administration. PLOS Medicine, 5, e45. https://doi.org/10.1371/journal.pmed.0050045 
[6] Cipriani, A., Furukawa, T.A., Salanti, G., Chaimani, A., Atkinson, L.Z., Ogawa, Y., Leucht, S., Ruhe, H.G., Turner, E.H., Higgins, J.P.T., Egger, M., Takeshima, N., Hayasaka, Y., Imai, H., Shinohara, K., Tajika, A., Ioannidis, J.P.A. and Geddes, J.R. (2018) Comparative Efficacy and Acceptability of 21 Antidepressant Drugs for the Acute Treatment of Adults with Major Depressive Disorder: A Systematic Review and Network Meta-Analysis. The Lancet, 391, 1357-1366.

https://doi.org/10.1016/S0140-6736(17)32802-7

[7] Matsuoka, K., Kato, K., Takao, T., Ogawa, M., Ishii, Y., Shimizu, F., Masuda, J. and Takada, A. (2016) Concentrations of Various Tryptophan Metabolites Increase in Patients of Diabetes Mellitus Compared to Healthy Aged Male Adults. Diabetology International, 8, 69-72. https://doi.org/10.1007/s13340-016-0282-y

[8] Takada, A., Shimizu, F. and Masuda, J. (2018) Measurement of Plasma Tryptophan Metabolites: Clinical and Experimental Application for Depression and Stress States Assessment. In: Dragoi, C.M. and Nicolae, A.C., Eds., Melatonin-Molecular Biology, Clinical and Pharmaceutical Approaches, IntechOpen, London, 143-160. https://doi.org/10.5772/intechopen.78560

[9] Shimizu, F., Ishii, Y., Ogawa, M., Takao, T., Matsuoka, K., Kato, K. and Takada, A. (2018) Plasma Levels of Tryptophan Metabolites in Healthy Young and Old Men and Women, and Patients of Type 2 Diabetes Mellitus (T2DM). Obesity: Open Access, 4, 1-9. https://doi.org/10.16966/2380-5528.138

[10] Takada, A., Shimizu, F. and Masuda, J. (2019) Plasma Levels of Tryptophan Metabolites in Patients of Type 2 Diabetes Mellitus. In: Watson, R. and Preedy, V., Eds., Bioactive Food as Dietary Interventions for Diabetes, 2nd Edition, Academic Press, Cambridge, 265-276. https://doi.org/10.1016/B978-0-12-813822-9.00017-5

[11] Tomioka, H., Masuda, J., Takada, A. and Iwanami, A. (2020) Comparison Age and Gender Differences of Tryptophan Metabolites in Patients of Major Monopolar and Bipolar Depression. Food and Nutrition Science, 11, 172-185. https://doi.org/10.4236/fns.2020.113013

[12] American Psychiatric Association (2013) Diagnostic and Statistical Manual of Mental Disorders 5th Edition (DSM-5). APA, Washington DC. https://doi.org/10.1176/appi.books.9780890425596

[13] Guy, W. (1976) Clinical Global Impressions ECDEU Assessment Manual for Psychopharmacology, Revised (DHEW Publ. No. ADM 76-338). National Institute of Mental Health, Rockville, 218-222. https://doi.org/10.1037/e591322011-001

[14] Zung, W.W.K. (1965) A Self-Rating Depression Scale. Archives of General Psychiatry, 12, 63-70. https://doi.org/10.1001/archpsyc.1965.01720310065008

[15] Hamilton, M. (1960) A Rating Scale for Depression. Journal of Neurology, Neurosurgery, and Psychiatry, 23, 56-62. https://doi.org/10.1136/jnnp.23.1.56

[16] Maes, M. (1993) A Review on the Acute Phase Response in Major Depression. Reviews in the Neurosciences, 4, 407-416. https://doi.org/10.1515/REVNEURO.1993.4.4.407

[17] Oxenkrug, G.F. (2010) Tryptophan Kynurenine Metabolism as a Common Mediator of Genetic and Environmental Impacts in Major Depressive Disorder: The Serotonin Hypothesis Revisited 40 Years Later. Israel Journal of Psychiatry and Related Sciences, 47, 56-63.

[18] Réus, G.Z., Jansen, K., Titus, S., Carvalho, A.F., Gabbay, V. and Quevedo, J. (2015) Kynurenine Pathway Dysfunction in the Pathophysiology and Treatment of Depression: Evidences from Animal and Human Studies. Journal of Psychiatric Research, 68, 316-328. https://doi.org/10.1016/j.jpsychires.2015.05.007 
[19] Mann, J.J., Malone, K.M., Sweeney, J.A., Brown, R.P., Linnoila, M., Stanley, B. and Stanley, M. (1996) Attempted Suicide Characteristics and Cerebrospinal Fluid Amine Metabolites in Depressed Inpatients. Neuropsychopharmacology, 15, 576-586. https://doi.org/10.1016/S0893-133X(96)00102-9

[20] Mann, J.J. and Arango, V. (1992) Integration of Neurobiology and Psychopathology in a Unified Model of Suicidal Behavior. Journal of Clinical Psychopharmacology, 12, 2S-7S. https://doi.org/10.1097/00004714-199204001-00001

[21] Perroud, N., Neidhart, E., Petit, B., Vessaz, M., Laforge, T., Relecom, C., La Harpe, R., Malafosse, A. and Guipponi, M. (2010) Simultaneous Analysis of Serotonin Transporter, Tryptophan Hydroxylase 1 and 2 Gene Expression in the Ventral Prefrontal Cortex of Suicide Victims. American Journal of Medical Genetics Part B, Neuropsychiatric Genetics, 153, 909-918. https://doi.org/10.1002/ajmg.b.31059

[22] Bach-Mizrachi, H., Underwood, M.D., Kassir, S.A., Bakalian, M.J., Sibille, E., Tamir, H., Mann, J.J. and Arango, V. (2006) Neuronal Tryptophan Hydroxylase mRNA Expression in the Human Dorsal and Median Raphe Nuclei: Major Depression and Suicide. Neuropsychopharmacology, 31, 814-824. https://doi.org/10.1038/sj.npp.1300897

[23] Boldrini, M., Underwood, M.D., Mann, J.J. and Arango, V. (2005) More Tryptophan Hydroxylase in the Brainstem Dorsal Raphe Nucleus in Depressed Suicides. Brain Research, 1041, 19-28. https://doi.org/10.1016/j.brainres.2005.01.083

[24] Sarriaz, M.J., Cabre, P., Martinez, E. and Artigas, F. (1990) Relationship between Serotonergic Measures in Bloos and Cerebrospinal Fluid Simultaneously Obtained in Humans. Journal of Neurochemistry, 54, 783-786. https://doi.org/10.1111/j.1471-4159.1990.tb02319.x

[25] Owen, F., Chambers, D.R., Cooper, S.J., Crow, T.J., Johnson, J.A., Lofthouse, R. and Poulter, M. (1986) Serotonergic Mechanisms in Brains of Suicide Victims. Brain Research, 362, 185-188. https://doi.org/10.1016/0006-8993(86)91415-0

[26] Arango, V., Underwood, M.D., Gubbi, A.V. and Mann, J.J. (1995) Localized Alterations in Pre- and Postsynaptic Serotonin Biding Sites in the Ventrolateral Prefrontal Cortex of Suicide Victims. Brain Research, 688, 121-133. https://doi.org/10.1016/0006-8993(95)00523-S

\section{Abbreviation}

tryptophan (TRP), serotonin (5-HT), 5-hydroxyindole acetic acid (5-HIAA), indole-3-acetic acid (IAA), kynurenine (KYN), selective serotonin uptake inhibitor (SSRI), serotonin epinephrine reuptake inhibitor (SNRI), clinical global impression-severity scale (CGI-s), self-rating depression scale (SDS), Hamilton depression rating scale(HDRS). 